\title{
O narrador performático em Rioseco, de Manuel Rui Monteiro
}

\author{
Karina de Almeida Calado*
}

\begin{abstract}
RESUMO
Este texto tem o propósito de analisar a construção do narrador no romance Rioseco, de Manuel Rui Monteiro, a partir do pressuposto de que a organização discursiva na qual ele se enuncia permite considerá-lo como o "narrador performático", conforme operador teórico cunhado por Terezinha Taborda Moreira (2005). Esse narrador realiza a proposta de recuperação da oralidade da cultura tradicional angolana, lançada no projeto estético do autor em reflexões como "Eu e o outro - o invasor ou em poucas três linhas uma maneira de pensar o texto" (1985) e "Da escrita à fala" (2004). Retomar essa oralidade é, para Manuel Rui Monteiro, a forma de inscrever a identidade angolana no processo de apropriação da escrita, símbolo da cultura do outro.
\end{abstract}

Palavras-chave: Narrador. Performance. Oralidade. Ancestralidade.

Para iniciar esta discussão cabe considerar o que nesta se tomará como performance e, como se vai analisar o processo de construção do narrador no romance Rioseco (1997), de Manuel Rui Monteiro, nada melhor do que convocar as palavras do próprio autor para se entender como a performance é pensada e instalada em seu texto. Manuel Rui Monteiro considera que na performance, inerente a toda narrativa oral, incluem-se os elementos que circundam o texto (água, som, luz, árvores, harmonia): “[é] texto porque [há] gesto (...) dança (...) ritual” (MONTEIRO, 1985). Já a escrita caracteriza-se pela ausência da performance, visto que o seu processo de criação e de leitura é um ato solitário. Nessa dualidade parece fundar-se o projeto ficcional, no qual o autor aponta a necessidade de se apoderar do canhão inimigo, a escrita, o que, para ele, significa transformá-la, submetê-la à oralidade; ou seja, ainda que o seu texto esteja escrito, mantê-lo "oraturizado e oraturizante" (MONTEIRO, 1985):

Vou é minar a arma do outro com todos os elementos possíveis do meu texto. Invento outro texto. Interfiro, desescrevo para que conquiste a partir do instrumento de escrita um texto escrito meu,

* Pontifícia Universidade Católica de Minas Gerais - PUC Minas. Bolsista Capes. Uma versão deste trabalho foi apresentada no XI Congresso AIL, UNICV-Mindelo/Cabo Verde, em julho de 2014. 
da minha identidade. Os personagens do meu texto têm de se movimentar como no outro texto inicial. Têm de cantar. Dançar. Em suma temos de ser nós. "Nós mesmos". Assim reforço a identidade com a literatura. (MONTEIRO, 1985, p. 2 - destaques do autor).

As palavras de Manuel Rui Monteiro apontam para uma transgressão no modelo de escrita; um fazer literário que recupere a voz e, com ela, toda a gestualidade do ritual coletivo, da magia que envolve o contar/ouvir estórias. Para ele, submeter a escrita à oralidade é inscrever e reforçar a sua identidade, em oposição à identidade do outro.

O projeto de uma escrita transgressora realizar-se-á na maneira como o autor construirá discursivamente o narrador. Como propõe Bakhtin, o narrador realizará o ponto de vista de seu autor e fará isso na maneira como organiza o discurso, a linguagem e o objeto de narração: "por trás do relato do narrador nós lemos um segundo, o relato do autor sobre o que narra o narrador, e, além disso, sobre o próprio narrador." (BAKHTIN, 1993, p. 118).

Moreira (2005) concebe a construção do narrador em narrativas africanas, tomando o exemplo de Terra sonâmbula, de Mia Couto, dentre outros, como um processo de metamorfose; um diálogo entre o oral e o escrito em que o narrador desenvolve um jeito de contar que recria esteticamente o contador de histórias das sociedades tradicionais, no caso, da sociedade tradicional moçambicana. Segundo a pesquisadora, na construção desse narrador há um princípio de organização discursiva que é próprio do narrador tradicional. Nesse processo de substituição surge um "narrador metamorfoseado", entendido pela estudiosa como "narrador performático".

Moreira enfatiza que esse procedimento não se trata de uma representação da oralidade, mas de uma reterritorialização do corpo do narrador oral. Para ela, há na narrativa a inscrição de "uma matéria corpórea figurada na e pela própria escrita” (MOREIRA, 2005, p. 49), que seria a presentificação do corpo cultural do contador de histórias instalado no texto. Esse narrador é retirado do espaço de sua "existência cotidiana" e se materializa como "referência de si próprio. (...) Ao mesmo tempo, encarnando a palavra, ele funda com cada acento de voz, cada sonoridade, cada voz que atravessa a sua própria, o espetáculo que lhe dá concretude." (MOREIRA, 2005, p. 51).

Refletir sobre a escrita de Manuel Rui Monteiro torna pertinente fazer algumas observações sobre a mímese, a partir de estudos feitos por Luiz Costa Lima (1980) e Walter Benjamin (2008). O primeiro crítico pensa a mímese como um modo de representação social, que apresenta um caráter mutável e estabelece uma 
fina sintonia com a dinâmica da sociedade, ao longo da história. Tal concepção converge com o que postula Benjamin (2008), ao afirmar que os processos miméticos guardam uma estreita relação com a sua época. Ao problematizar a validade do conceito de mímese para pensar as obras que marcam a modernidade, Costa Lima faz-nos compreender que a mímese sempre existirá, pois se trata de uma faculdade natural do ser humano, conforme Benjamin. O que muda são os modos de representação, ou, para Benjamin, transformam-se as formas de criar semelhanças.

O rompimento com o modelo de escrita literária "metropolitano" estará no cerne da criação de um novo padrão de imitação na narrativa de Manuel Rui Monteiro. A recuperação da oralidade da cultura tradicional angolana referenciará o novo modo de representação e a nova forma de organização do texto escrito será tecida a partir da relação de semelhança com uma organização do mundo que é oral e que reverbera na ancestralidade do escritor.

O narrador de Rioseco tomará dois modelos de referência para construir a estória. O primeiro modelo é o da cena ritual da contação, a partir do qual gestará a performance, transportando paisagens, sonoridades, cheiros, corpos e gestualidades de personagens. $\mathrm{O}$ segundo modelo de referência será o conflito entre os valores culturais ancestrais e o contexto social e político do país, contemporâneo ao tempo da narrativa. Essas referências conduzirão a performance do narrador e o agenciamento do diálogo entre as personagens na estruturação da narrativa.

Para Benjamin (1994), narrar é uma faculdade de intercambiar experiências. E é como intercâmbio de experiências que se construirá a narração em Rioseco. O narrador é o ser dotado da experiência de conhecimento da realidade, da memória e dos costumes e tradições de seu país. Na organização do enredo, ele trará a estória do casal de velhos fugitivos da guerra civil de Angola, Noíto e Zacaria, ambos do Sul; ela, de etnia Umbundo, natural do Huambo, e ele, do povo Tchokwé, natural do Kubango. O casal, fugindo há dez anos da morte, deixando tudo para trás, chega a Luanda, onde é aconselhado por uma feirante a ir buscar refúgio na ilha, lugar aonde, segundo ela, a guerra não havia chegado.

A narrativa encenará a experiência do casal na viagem de deslocamento para a ilha e no processo de adaptação à nova vida, num espaço em que tudo era diferente do seu lugar de origem. O casal de velhos cumpre, por excelência, o papel de trazer para a narrativa o acervo de memórias do país dominado pelo colonialismo português, da luta pela independência, da experiência da guerra e das guerrilhas. Essa memória funcionará como um importante recurso de contraponto entre a colonização e a vivência no país pós-independência, devastado pela guerra civil e pelo descaso de um governo autoritário e corrupto. 
A ilha é o espaço escolhido para encenar o entrecruzamento de línguas, de culturas, de tempos, de histórias e de discursos, e, claro, a tensão que é instalada em todo espaço de encontro entre diferentes. Espaço que sugere a representação metonímica de Angola e, ao mesmo tempo, funciona como contraponto entre o país que se tem e a utopia do país novo, a ser criado a partir de uma visão integradora das diferenças, da coexistência das culturas do rio e do mar, do interior e do litoral, do velho e do novo, do passado e do presente.

Os contrastes são evidentes na narrativa. Há coexistência das diferenças culturais, étnicas e linguísticas, de forma respeitosa, mas também há o desrespeito. Há a convivência respeitosa e harmônica entre ser humano e natureza, como também há o desequilíbrio. Há a preservação de práticas culturais tradicionais, porém também há a tentativa de descaracterização da cultura tradicional. Há as práticas éticas e também as corruptas. Em geral, as personagens ligadas ao desrespeito, ao desequilíbrio, à descaracterização e às práticas corruptas são as invasoras e representam, de alguma forma, o governo angolano. Na voz narrativa, evidencia-se que "a ilha, ao fim e ao cabo, tinha a vantagem do resumo." (MONTEIRO, 1997, p. 134).

Ao iniciar a narrativa pela viagem de travessia para a ilha, que é habitada por uma comunidade de pescadores que cultiva práticas tradicionais, observa-se uma metáfora da viagem de retorno à ancestralidade. Na ilha, o narrador encontrará as marcas identitárias de seu país e, entre elas, a tradição oral.

O narrador de Rioseco é construído de modo a transformar o leitor em ouvinte e trazê-lo para o interior da narrativa, já a partir dos primeiros gestos sugeridos em sua enunciação. O olho do leitor vê com o olhar do homem que, na gestualidade inscrita pelo narrador, é descrito de pé, calça verde-oliva arregaçada até os joelhos, mão direita na barba rala a esbranquear, e que está de frente para o mar, a fitar o pescador que vinha pelo canal abastecer suas vasilhas de água e levá-las de volta para a ilha. Na sequência, o leitor tem seu olhar deslocado para os gestos da mulher que está sentada sobre sua trouxa, cachimbo na boca, a guardar, sob si, os seus pertences. Desse modo, a cena da contação é construída e o leitor, apresentado a Zacaria e a Noíto, acompanhará a estória desses viajantes na travessia para a ilha, pelas águas que lhes mudarão o destino. A estratégia de incluir o que está sendo contado nas percepções do leitor fará parte da performance do narrador ao longo de toda a estória e caracterizará a vocalidade (ZUMTHOR, 1993) da narrativa.

Os elementos evocados por Manuel Rui Monteiro como essenciais à recriação da magia do ritual da contação (água, som, luz, árvores, harmonia) ganham vida na tessitura narrativa e tornam-na sonora e visual. Entre imagens, sons e cheiros, o leitor vai adentrando cada vez mais nos espaços "cênicos" criados pelo narrador: 
Os ramos de palmeira, já secos, que delimitavam o quintal na parte de trás da casa, xoxoalhavam se abanando nas folhas, ventar de fresco com o sol em sua passagem infalível de aparecer e desaparecer por detrás das nuvens. E o mar fervia-se ali defronte, agora. Com ondas que dorsavam umas por cima das outras, rebentando ao nascer e morrer da espuma transbordante de cheiro a maresia e, para além, como zunzunando de enxame nos ouvidos, outros barulhos, impressão de longínquos, roncavam marulhares oceânicos, sem sílaba mas revoltosos e que não eram, de certeza, das águas já passadas em viagem. (MONTEIRO, 1997, p. 22-23).

Observa-se que o campo lexical é intencionalmente mobilizado para que o leitor visualize as imagens, ouça os sons e sinta os cheiros da natureza: ramos, xoxoalhavam, ventar; sol, aparecer, desaparecer; ondas, espuma, maresia, zunzunando, roncavam, marulhares. As várias palavras relacionadas à percepção sonora evidenciam, conforme registrou Moreira, a capacidade desse narrador de assumir a qualidade auditiva do texto até o extremo (MOREIRA, 2005, p. 84).

$\mathrm{Na}$ organização discursiva, o narrador traz a beleza da vida que permeia a narrativa. $\mathrm{O}$ texto é tecido com cores, formas e movimentos próprios da paisagem encenada:

O céu, todo inteiro de azul, mas, num sem querer, entregado a receber-se de cinzento, protegendo o sol. O vento a violar mais a pacatez na barriga das águas que se agitavam maneira de fome para a subida, em curvas lindas. Simulando pensamentos. Na avidez de espuma. E as árvores, os coqueiros e as casuarinas, erguiam seu sabido cântico de saborear as manias do tempo. Os miúdos corriam. (MONTEIRO, 1997, p. 224).

Esse jeito de contar faz com que o narrador lance mão de recursos estilísticos, semânticos e sintáticos para atingir o seu objetivo de tornar o gesto de narrar semelhante à coisa narrada. Nesse sentido, são características da narrativa as constantes personificações de elementos da natureza, como o mar, as árvores, a terra e o vento. É notório, por exemplo, que quando são narradas passagens que evocam a imagem do mar, há uma estruturação frasal que busca imitar o fluir das águas, o vai e vem das ondas, a sua agitação ou calmaria:

O mar como se fosse Deus e quem sabe se Deus não andará por aí disfarçado nessa água tão grande que faz o que quer? (MONTEIRO, 1997, p. 34).

Ali, tudo era diferente. Tudo coisas do mar que bravava mudando a sua fala e, pelo anoitecer, em vezes mais calmo, mexendo-se, devagarinho, pela terra adentro até dar água às portas do bengalô 
num pequeno lago manso que se espalhava rodeando de espelho se mexendo pelos ramos dos coqueiros todos dengosamente em dança. (MONTEIRO, 1997, p. 273).

A vida na ilha parece imitar o movimento das águas do mar. É como se elas antecipassem a maneira como os acontecimentos surgirão na narrativa. Quando o mar está calmo, há a indicação de que as coisas na ilha estão ou serão tranquilas. No entanto, quando ele está agitado, percebe-se que a ilha viverá momentos tensos e difíceis. A sintonia entre mar e vida é mais uma sugestão de que tudo na ilha está intimamente ligado entre si, ou em harmonia, como considerou Manuel Rui Monteiro, o que, na concepção de Moreira (2005), é a reafirmação da ordem cósmica entre seres e coisas, marca constitutiva da experiência do homem africano:

Era só escalar, sal e pra lhes receber no sol. Também os de ir nos longes do mar, aproveitando vontades do vento, sol e lua, nos tais para lá de dar a volta à ilha, de remo e vela, o fogo-fogareiro, carvão areia e pedras, na canoa de pernoita, ou no dongo grande, mais colectivo, saído, no princípio das estrelas para voltar na meninez do sol, os homens do mar que navegam até quase perderem de vista o imbondeiro em ponto mais alto, muito por cima da encosta do ancoradouro, primeiro embarque marítimo de Noíto e Zacaria. Também eles. Também eles falavam. Que era a lua que mudava o vento. E era a maré que mudava a lua. E era o calor do sol que mudava a berrida do vento. Falavam os barqueiros quando iam para a pesca. Mas quem havia mudado isso tudo era a Kambuta, falavam os barqueiros quando regressavam da pesca. (MONTEIRO, 1997, p. 215).

Observa-se uma cuidadosa estratégia de repetição de letras, sons e palavras, evidentes na construção de aliterações e anáforas ao longo desse trecho. Esses recursos corroboram com a sonoridade e a plasticidade do texto. Conforme apontou Moreira, ao considerá-los em narrativas moçambicanas: "por meio da sintaxe, e às vezes além ou aquém dela, o ritmo suscita na língua relações imprevistas, provoca aproximações insólitas, abre-se em plena metáfora viva." (ZUMTHOR apud MOREIRA, 2005, p. 165).

A partir das considerações de Moreira (2005) sobre a gestualidade, percebese que os recursos sonoros encenados pelo narrador de Rioseco fazem parte da realização de movimentos que conferirão ritmo próprio à sua narrativa. $\mathrm{O}$ ritmo estruturará a relação entre a construção sonora e sintática do texto e a imagem que ela sugere. Isso explica, por exemplo, a sensação que se tem, ao ler passagens que evocam o mar, de que ele é percebido sonora e visualmente no campo léxicosemântico e nos movimentos frasais: 
O ritmo é objetificado pelo corpo do narrador figurado na escrita, mais do que por suas palavras, embora sejam as palavras que sugiram os movimentos do corpo, pelo efeito icônico que provocam. O corpo figurado do narrador, ao realizar os movimentos, revelanos, através de determinados gestos, a estrutura e a textura das imagens verbalmente evocadas. Nos textos, o gesto mantém uma relação de similitude com a palavra que ele encadeia e combina. (MOREIRA, 2005, p. 167).

O ritmo pode também ser percebido na tensão com que a guerra é inscrita na dicção da frase, que é caracterizada pela ausência de lógica coesiva e de pontuação. Evidencia-se que a própria estruturação frasal imita essa tensão da situação relatada:

Da maneira, explica Zinha chorando com as mãos tapando os olhos. Que haviam sido os da mão-preta, grupo de gregos afamados de assalto, roubos e morte de pessoas, do outro lado, em cavalos até de noite entrando nas escolas de falta de luz e catorzar nas miúdas esses mesmos tais próprios que mandaram escrever na escola aqueles quês para depois ainda iam matar no professor Dos Mais e que os ó-dês saídos aí nos barcos de pneu, procuraram tudo o que era gente crescida, à mão de semear, mais-velhos pescadores. (MONTEIRO, 1997, p. 462-463).

A semântica inscrita no título da narrativa é sugestiva da presença do rio na estória, mesmo que, numa primeira impressão, ele não tenha água em seu curso; um "rio seco", ou, pensando no final da narrativa, a ideia de ilha termine quando Zacaria descobre que, na maré baixa, a ilha se transforma em península, cujo final é um rio seco, que faz contato com o continente.

A estória começa diante do mar e termina diante do rio. Mar e rio pautam reflexões constantes de Noíto e Zacaria. Não é exagero dizer que o elemento água atravessa toda a narrativa e é essencial à construção do enredo: o casal faz a travessia para a ilha conduzido por um pescador que ia ao continente buscar água potável; o rio é definidor da cultura de Noíto e Zacaria; já o mar, é definidor da cultura da ilha; do mar sai o sustento dos ilhéus: a pesca para consumo e comércio; a estiagem instala um conflito narrativo que permeia toda a segunda parte do livro; a força de feiticeira de Noíto está relacionada à sabedoria das águas: ela tinha sangue da Kianda (deusa das águas), adivinhava onde havia água subterrânea e amarrava e desamarrava a chuva; no final da narrativa, após a morte de Zacaria, que é seguida de uma chuva intensa, surge um rio que corre da ilha para o continente e, segundo Noíto, o rio era o próprio Zacaria. Por meio de seu campo lexical (mar, 
rio, chuva), a água aparece tanto na voz do narrador quanto no agenciamento das vozes das personagens, como se observa nas falas de Kwanza, Zacaria e Noíto, respectivamente:

Mas o mar é muito mais grande que todos os rios. Na contra-costa, já me explicaram, a gente fica só a olhar e não tem outro lado da água, é tudo azul até no fim que não se vê. O mar é muito grande e as ondas dele têm muito mais força que os rios todos juntos. Xé!"

"O mar é só assim por causa dos rios que lhe trazem a água. Os rios é que enchem o mar. Nenhum dia viste um mar encher um rio, já falei. Isso é tudo água que vem da nossa terra. Sem a nossa terra, sem os rios que atravessam muito tempo, devagar e depressa, depressa e devagar, a secar e a encher na chuva, onde é que estava o mar? Sem a nossa terra, onde nascem os rios, o povo daqui não tinha mar para pescar. Não há mar sem rio, eu já falei. (MONTEIRO, 1997, p. 90).

A chuva é uma coisa que não está aqui nem a gente sabe o sítio dela. Só mesmo quando ela cai a gente vê. E quando acaba já não está. O mar está sempre. E o mar nunca entrou na chuva. O mar também nunca entrou no rio. A chuva entra no mar. O rio entra no mar. Essa barriga grande das águas do mar da Kianda tem o sangue da chuva e do rio. A barriga da chuva é muito grande e não anda a receber nas pessoas como faz o mar. É por isso que vocês querem a chuva. Eu também. Para encher na barriga do rio. Para encher nas nossas barrigas. E na barriga do mar. (MONTEIRO, 1997, p. 338).

Somados à água, os outros três elementos naturais (terra, ar e fogo) estão dispostos harmonicamente e são constituintes da estória. Se Zacaria é o homem do rio, ou o próprio rio, e Mateus é o homem do mar, ou propriamente o mar, Kwanza é a síntese entre rio e mar (avô do rio e pai do mar), enquanto Noíto é a metáfora da terra angolana. Essa metáfora é evidente na maneira como ela se relaciona, cultiva e necessita dos instrumentos de trabalhar a terra (pá e enxada) e precisa desbravar todo o espaço que compõe a ilha: "desejava rasgar o corpo da terra com uma enxada (...) finalmente, tinha o corpo da ilha todo na mão." (MONTEIRO, 1997, p. 51, 216). A terra, como o rio ou o mar, não é apenas personificada, mas também sacralizada.

Toda a narrativa encena o processo de conhecimento e desbravamento da ilha. Sabemos que a ilha "era quase a experiência que faltava". Noíto afirmava já ter conhecido quase todo o restante das terras angolanas durante a sua vida nas guerrilhas. Ela também será a personagem que terá a propriedade feiticeira de se relacionar e dominar o ar (vento) e o fogo. É descrita com o poder de mudar o vento para favorecer os pescadores e para atrair ou deslocar a chuva. No controle 
do fogo, era capaz de levá-lo nas mãos e não se queimar, bem como lançar o feitiço para que a cadeia em que os pescadores foram presos pegasse fogo e queimasse $o$ autor da denúncia, o professor Dos Mais, e os policiais.

A inscrição de gestos, danças e rituais é necessária, segundo Manuel Rui Monteiro, à realização plena do texto e é observada com maestria na personagem Noíto. Nos trechos a seguir, tomam-se duas cenas como amostras dos gestos projetados na personagem. Na primeira cena, Noíto chora, dança e lamenta o desconhecimento e a desvalorização, por parte de pessoas da cidade, de um importante costume do interior do país. Na segunda cena, de uma profunda beleza descritiva, Noíto está nua da cintura para cima, diante de seu pilão, e os movimentos de sua batida são encenados na própria construção léxico-sintática:

Aí, Noíto começou a chorar, dançando com as mãos sobre a cabeça, "gente que tem tanta comida, gente que tem um barco, gente tão rica, como é que esta gente não gosta de abelhas nem sabe o que é mel?" E deu em xinguilar com o corpo rolando sobre a areia. (MONTEIRO, 1997, p. 181).

Ficou só com o pano que lhe tapava o corpo para baixo do umbigo. Os seios assim. A baloiçar, flácidos, esteirados mas presentes no ritmar dos braços dela sobre o pilão, alados braços quando subia o pau a maltratar o milho que se esquivava sob cada arremesso dela e depois se juntavam grãos nas bordas do fundo do pilão e depois os braços apertados nos sovacos tão pequenos dela após abertos (...). Pau no ar, pau no milho, pau no ar pau no milho, a ofegar, bafo de som sonante sempre na boca (...). (MONTEIRO, 1997, p. 239).

Como antes mencionado, na ilha se entrecruzam os saberes culturais do interior, portados nas vozes de Noíto e Zacaria, e os saberes culturais do litoral, inscritos na comunidade. No pilão de Noíto, por exemplo, está registrada a marca da origem étnica de Zacaria, uma tatuagem, que é descrita para Kwanza da seguinte forma: "Isto foi feito com um ferro em brasa. São desenhos da terra dele. Os quiocos sempre souberam cativar as mulheres com desenhos, caça e sabedoria." (MONTEIRO, 1997).

Nem sempre harmônica, estabelece-se uma relação de troca de saberes, evidenciada na convivência de Noíto com Kwanza, com outras mulheres e com os demais ilhéus. Ela ensina o hábito de armazenar água e comida e aprende a confeccionar balaios para vender. Esse entrecruzamento faz com que vários aspectos do espaço e da cultura de cada lugar sejam evocados. Como registra Moreira, "por vezes a voz do narrador é atravessada por vozes outras, oriundas de saberes os mais diversos, as quais se instalam nos textos inscrevendo nele um tipo 
de saber acumulado pela experiência histórica" (MOREIRA, 2005, p. 129), e que, no romance em estudo, se pode visualizar no seguinte trecho:

E o Boaçorte entregava-se, dócil, àquelas mãos de mulher, pequenas e de pele enrugada, para Noíto dizer satisfeita:

"Hoje estou muito contente. E o teu barco parece o meu comboio a atravessar eucaliptos. Um dia vais-me emprestar para eu vir sozinha mais o meu neto Kwanza."

"Pai, a avó já sabe pescar e ximbicar"."

"E fazer balaios" - acrescentou Zinha.

"Mas ainda o que eu quero aprender mesmo é naquela renda no dedo grande do meu pé. Na mão já sei!" (MONTEIRO, 1997, p. 133).

Note-se que na fala de Noíto estão expressas as palavras "comboio" e "eucaliptos" como marcas identitárias do seu lugar de origem e que, em oposição à cultura da ilha, estabelecem um correspondente comparativo. Já nas falas de Kwanza e Zinha são inscritos saberes da comunidade que são aprendidos por Noíto. Essas vozes transformam o texto num palco de espetáculo cênico por onde o encontro de culturas diversas que formam o país vai sendo encenado.

No modo como é escrito o nome do barco "Boaçorte" e na palavra "ximbicar" observa-se uma demonstração de um estilo característico do autor: a subversão da escrita oficial e a inserção do léxico e da sintaxe de vários dialetos angolanos, a exemplo do quimbundo, do umbundo e do quicongo. Esse estilo denota mais uma convergência com o objetivo de recuperação da oralidade, que também passa pela apropriação do português na escrita angolana. A língua portuguesa também se revela na voz de Noíto como fator e ideal de unidade entre todos os angolanos:

$\mathrm{Na}$ mata foi assim. Os camaradas guerrilheiros vinham de todo o lado. Cada um na sua língua. E entendiam-se. Essa língua dos tugas, que não é só deles, é nossa, uniu-nos muito. Afinal uma língua não é de ninguém! A língua é de quem aprendeu. (MONTEIRO, 1997, p. 113).

No discurso didático do narrador, tem-se acesso ao conhecimento do imaginário da ilha. Inscreve-se o acervo de ritos, mitos e símbolos. Recupera-se para o leitor, por exemplo, a maneira como, naquele lugar, se fazem as cerimônias de velório e de funeral. Lá, a morte é um grande acontecimento, do qual fazem parte: a mobilização de todas as pessoas da comunidade para velar o falecido, a fartura de comidas e bebidas, a confecção do caixão e a escolha das cores para a mortalha, o

1 Do quicongo "ximbica": remar à vara. 
pranto, o carpir e a entoação de cânticos. O ritual de morte ainda envolve o anúncio do óbito, que varia de acordo com a origem da pessoa: no de Mateus, pescador e filho de um homem das terras do rio grande, a batida foi feita com remos nos barcos, pelos pescadores, e, por Zacaria, com o xingufo ${ }^{2}$. Há o cortejo por terra e por mar; neste, com um modo especial de ximbicar os barcos, que se movem de um lado para o outro. A viúva manifesta o luto trancada por um mês em um quarto.

A fala do narrador é sugestiva da beleza imagética e sonora desse ritual: "a noite e as estrelas, estranharam-se naquela conversa chorada no eco entre o bater dos remos e o delírio espiritual do xingufo." (MONTEIRO, 1997, p. 477). Ao evocar a importância do ritual de morte na comunidade, o narrador também realiza um contraponto em relação ao desrespeito com que os mortos são tratados na cidade, onde muitos são enterrados como indigentes em valas comuns, quando não são deixados expostos para se decomporem em estradas. A crítica instaurada vai ao encontro do que problematiza Benjamin, ao afirmar que, na sociedade burguesa, a morte vai deixando de ser um espetáculo coletivo (BENJAMIN, 1994, p. 207). Gesto esse que ele associa à desvalorização do potencial narrativo, pois:

é no momento da morte que o saber e sabedoria do homem e sobretudo de sua existência vivida - e é dessa substância que são feitas as histórias - assumem pela primeira vez uma forma transmissível. Assim como no interior do agonizante desfilam inúmeras imagens - visões de si mesmo, as quais ele havia se encontrado sem se dar conta. (BENJAMIN, 1994, p. 207).

No sentido exposto por Benjamin, é na projeção da gestualidade e das lembranças de Noíto diante do rio, transfiguração do corpo morto de Zacaria, que o narrador recupera para o leitor a memória retrospectiva dos acontecimentos de toda a narrativa. Tal estratégia pode ser interpretada, também à luz de Benjamin, como um esforço para facilitar ao leitor "recontar" a estória.

A relação com os mitos é inserida no discurso do narrador e nota-se que ela vai regendo as ações e as interpretações das personagens. O principal mito registrado é o da Kianda, divindade protetora da ilha. Em sua homenagem são realizadas festividades e oferendas. Além da Kianda, há também as superstições relacionadas aos animais, aos objetos e à natureza, de modo geral. Nesses mitos, a comunidade encontra a força explicativa para todos os acontecimentos, entre os quais podemse destacar: a preservação da tradição e o cumprimento de promessas à Kianda garantem tempos de bonança; a instalação das abelhas relaciona-se à fartura; já a saída das abelhas, aos momentos difíceis; a ausência de folhas sobre a água

2 Do umbundo: tambor. 
transportada para casa, por Noíto, estaria na origem dos males acontecidos na ilha; a faca é relacionada à sorte de quem a presenteou e à de quem a recebeu; já o uso com coisas desonestas explica a desventura de Zacaria, ou, ainda, essa desventura estaria ligada ao assassinato dos porcos e das árvores. Observa-se, no trecho seguinte, como a ideia do mito organiza o discurso do narrador e antecipa a fala de Noíto:

A maka dos porcos, agora das árvores, do fogo posto e do carvão e, mesmo assim, Deus a proteger Zacaria. Ou seria um aviso para ele não vir tocar nas abelhas, nem lhes tirar no mel? Dava para hesitar. "Sabes, melhor era não mexermos nas abelhas; Deixar passar o tempo até eu ir no Caculo com a despesa de uma promessa." (MONTEIRO, 1997, p. 324).

O perfil de liderança e de guardiã de um precioso acervo de memórias e de sabedoria ancestral, aliado aos inúmeros feitos de interesse coletivo, faz com que a comunidade veja em Noíto o elo com a Kianda. Dividindo opiniões ao longo da narrativa, Noíto é considerada a representante, a herdeira sanguínea, tronco e cabeça, ou mesmo a própria Kianda. Capaz de interpretar os sinais em seu corpo e na natureza, ela se sabe a feiticeira, e a comunidade a nomeia de Kambuta: "espécie de mulher com boa estrela favor da Kianda." (MONTEIRO, 1997, p. 142).

No sentido atribuído por Nicolau Sevcenko (1998), Noíto é a representação do xamã. Ela é a personagem que tem o poder encantatório da linguagem: dança, conta histórias; exerce o importante papel de coesão e identidade social; o corpo sagrado no qual o espírito sagrado se materializa e se manifesta diante dos homens; a interlocutora entre o humano e o divino. Em Noíto está inscrita toda a força da oralidade da cultura tradicional angolana:

E ela começou a contar a estória toda da chuva desde o dia primeiro, maneira como Fiat e Zacaria haviam salvado o casco, maneira de acender o fogo, tudo, maiorizando ainda a quibia da faísca e o bengalô a estraçalhar-se em cima dele próprio como um xingue brinquedo menino que de tal forma contava e punha ênfase que Satumbo, Noíto a perceber, estava pembado nos olhos, certeza mais que absoluta, de ter sido ela a amarradora e desamarradora da chuva. (...) E começou a contar da chuva de uma maneira linda que parecia uma estória de enredo que Noíto seguia de canjonja. (MONTEIRO, 1997, p. 370 - 371).

Mas a chuva ninguém mais vai esquecer e ainda vão contar nos outros que ainda vão nascer depois de nós morrermos. (MONTEIRO, 1997, p. 456). 
Pode-se deduzir que, ao associar a Noíto o papel do xamã, o autor cumpre dois objetivos. O primeiro, de promover, por meio da personagem, o retorno à origem da narrativa, à oralidade primordial da cultura tradicional, presente na figura mágica e encantatória do xamã e no primitivismo da ilha. $\mathrm{O}$ segundo se instala no contraponto possível entre a representação do xamã e o governo angolano. $\mathrm{O}$ xamã, poder supremo na condução e na organização das sociedades primitivas, porém marginalizado pelas sociedades sedentárias, exerce, em Noíto, a força questionadora das práticas e do discurso do governo:

Eu conheço a nossa terra quase toda. Andei com os que lutaram contra os colonos. Carreguei aqui, estás a ver, comida e armas dos guerrilheiros. Estes meus pés se falassem vocês todos tinham que duas vezes para andar o que eles andaram. E os olhos, também para ver o que eles viram. Conheço quase todos os que lutaram. Não é como agora que andamos a lutar uns contra os outros só por causa dos cocos como eu vi, numa terra que tem mais cocos que pessoas E cuspiu de forma carregada. (MONTEIRO, 1997, p. 231).

$\mathrm{Na}$ ironia que permeia todo o discurso de Noíto, o governo sonhado pela luta de libertação não se concretiza e o país afunda no caos, tendo na guerra civil, na corrupção, na burocracia, no lixo, na miséria generalizada, na cólera e na malária, alguns exemplos desse caos. Contrapondo-se a essa realidade, a ilha funcionaria como representação alegórica e utópica da substituição de uma ordem desgastada por uma nova ordem, que estaria impressa em várias inscrições simbólicas: o desabamento do bengalô representaria o fim da estrutura que abrigava as pessoas do governo na ilha, o símbolo de sua expulsão; o incêndio na cadeia se apresentaria como o fim de uma estrutura repressiva; e as águas do rio seriam um símbolo da independência da ilha.

Com as mortes de Mateus e Zacaria, pode-se vislumbrar a morte do discurso segregador, "Eu sou só do mar" ou "Eu sou o rio", e a sua substituição pela imagem integradora que está presente em Kwanza e Noíto: mar e rio em diálogo, formando o uno. Na dinâmica dessa relação, o autor constrói a metáfora do futuro. Uma imagem que busca, ao recuperar o passado, construir o novo sobre os alicerces da sabedoria ancestral. 


\begin{abstract}
This text has the purpose of analyzing the construction of the narrator in the novel Rioseco, by Manuel Rui Monteiro, starting from the idea that the discursive organization in which he enunciates himself allows us to consider him as the "performatic narrator", according to the theoretical operator coined by Terezinha Taborda Moreira (2005). This narrator proposes the recovery of orality from the traditional Angolan culture, released in the author's aesthetic project in the following reflections: "Eu e o outro - o invasor ou em poucas três linhas uma maneira de pensar o texto" (1985) and "Da escrita à fala" (2004). The rescue of this orality is, for Manuel Rui Monteiro, the way of inscribing the Angolan identity in the process of appropriation of writing, a symbol of the other's culture.
\end{abstract}

Keywords: Narrator. Performance. Orality. Ancestry.

\title{
Referências
}

BAKHTIN, Mikhail. Questões de literatura e de estética: A teoria do romance. São Paulo: Unesp, 1993.

BENJAMIN, Walter. A doutrina das semelhanças. In: BENJAMIN, Walter. Obras escolhidas. Magia e técnica, arte e política. Tradução de Sérgio Paulo Rouanet. São Paulo: Brasiliense, 1987. V. 1, p. 108-113.

BENJAMIN, Walter. O Narrador: considerações sobre a obra de Nikolai Leskov. In: BENJAMIN, Walter. Obras escolhidas. Magia e técnica, arte e política: ensaios sobre literatura e história da cultura. Tradução de Sérgio Paulo Rouanet. São Paulo: Brasiliense, 1994. p. 197-221.

LIMA, Luiz Costa. Mímesis e modernidade: formas das sombras. Rio de Janeiro: Edições Graal, 1980.

MONTEIRO, Manuel Rui Monteiro. Eu e o outro - o invasor ou em poucas três linhas uma maneira de pensar o texto. Comunicação apresentada no ENCONTRO PERFIL DA LITERATURA NEGRA,1, São Paulo, Brasil, 23 maio 1985.

MONTEIRO, Manuel Rui Monteiro. Rioseco. Lisboa: Edições Cotovia, 1997.

MONTEIRO, Manuel Rui Monteiro. Da escrita à fala. In: Actas. $1^{\circ}$ Congresso Internacional de Teoria da Literatura e Literaturas Lusófonas. Coimbra: Almedina, 2005 . 
MOREIRA, Terezinha Taborda. O vão da voz: a metamorfose do narrador na ficção moçambicana. Belo Horizonte: Editora PUC Minas; Belo Horizonte: Edições Horta Grande Ltda., 2005.

SEVCENKO, Nicolau. No princípio era o ritmo: as raízes xamânicas da narrativa. In: PRADO JÚNIOR, Bento et al. (Org.) Narrativa: ficção e história. Rio de Janeiro: Imago Ed., 1998. p. 120-136.

ZUMTHOR, Paul. A letra e a voz: a "literatura" medieval. Tradução de Amálio Pinheiro e Jerusa Pires Ferreira. São Paulo: Companhia das Letras, 1993.

Submetido em: 31 de julho de 2015. Aceito para publicação em: 02 de outubro de 2015. 
